\title{
Factors Delaying Presentation of Sudanese Breast Cancer Patients: an Analysis Using Andersen's Model
}

\author{
Alaaddin M Salih ${ }^{1,2,3 *}$, Musab M Alfaki ${ }^{2,4}$, Dafallah M Alam-Elhuda ${ }^{5}$, Momin \\ M Nouradyem ${ }^{4}$
}

\begin{abstract}
Purpose: A multicenter, observational, cross-sectional study was conducted to assess factors delaying presentation of breast cancer cases. Materials and Methods: Data were collected from a pair of highly specialized referral centers, both located in the center of the Sudanese capital, Khartoum. For a total of 153 eligible respondents, durations of delay, clinicodemographic factors and reasons of referral were collected from our respondents through self-administered questionnaires. Logistic regression analysis and ANOVA were used to test the relation between periods of delay and different factors. Odd ratios (OR's) and their correspondent Confidence intervals (95\% CI's). Delay periods were studied with Andersen's model. Results: The average duration of delay in our study was $11.9( \pm 11.2)$ months. Only a quarter of our patients presented early within the first 3 months after onset of their symptoms. About $47.7 \%$ arrived later during the course of the first year, while it took beyond that for the last $27 \%$ to come. A prior diagnosis of $\mathrm{BC}$ was the only predictor of early presentation (for 3-12 months OR=9.6 (p<0.00), 95\% CI 9.55-9.75; for $>12$ months OR=9.3 (p<0.00), 95\% CI 9.33-9.33). Out of the 12 different reasons for delay given by our respondents, none showed a significant difference between patients presenting early or late. Financial incapacity (17.5\%), ignorance about BC (14.3), and misinterpreting symptoms $(\mathbf{1 2 . 7 \%})$ were the top three whys of delay. Conclusions: Our findings support existence of a non-uniform pattern of delay among Sudanese BC patients. Changing currently adopted awareness elevating strategies into much more inclusive approaches is strongly recommended.
\end{abstract}

Keywords: Breast cancer - delayed presentation - late - advanced stage - Sudanese women

Asian Pac J Cancer Prev, 17 (4), 2105-2110

\section{Introduction}

Breast cancer $(\mathrm{BC})$ is the most common female malignant with a constantly increasing incidence globally (Parkin, 2005). Approximately, one out of eight women has a lifetime risk of developing the disease $(12.9 \%)$ (Cancer Research, 2012). Incidence of BC is higher in developed nations compared to their counterparts, however, burden of the disease has been constantly changing to swift towards developing regions (Benson and Jatoi, 2012; Ferlay et al. 2015).

More than $70 \%$ of BC diagnoses in developed countries are made during early stages, either I or II, compared to only $20-60 \%$ that reported in low and middle-income countries (LMIC) (Unger-Saldaña, 2014). Such delayed diagnoses have been described as the main determinants of advanced stage BC (Unger-Saldaña, 2014; Fregene and Newman, 2005). Advanced cancers among Sudanese is a well-known issue since early eras. The world's oldest distally metastasized malignancy has been discovered in Sudan in an ancient antiquity (1200 BC) (Binder et al., 2014). Ever since, the problem persists and today it constitutes a major public risk in the country. There are two categories of delay, patient and system delays. Patient delay which occupies time interval from onset of symptoms till seeking medical advice. System or provider delay usually follows either the first clinical appointment or initiation of management.

\section{Materials and Methods}

\section{Study design and subjects}

This is a multicenter, observational, retrospective, cross-sectional study conducted in breast clinics of Bashaier University Hospital (BUH) and Khartoum Center for Radiation and Isotopes (RICK), Khartoum, Sudan. Both are leading tertiary centers highly specialized in managing breast conditions among Sudanese and east

${ }^{1}$ Faculty of Medicine, International University of Africa, ${ }^{2}$ National Academy of Health Sciences, ${ }^{4}$ National Ribat University and Central Police Hospitals, National Ribat University, ${ }^{5}$ Department of Community Medicine, Faculty of Medicine, University of Khartoum, Khartoum, Sudan, ${ }^{3}$ College of Medicine and Veterinary Medicine, University of Edinburgh, Edinburgh, UK *For correspondence:alaaddinsalih@yahoo.com 
African nationals. From October 2014 to September 2015, all eligible patients referred to either of the study facilities were considered. Inclusion criteria were: being a Sudanese female who had menarche, confirmed diagnosis with a standard triple assessment, cases of breast cancer should be of primary type, and accepting participation without compensation. Uncertain diagnoses, breast metastasis from another primary focus, and comparison subjects with proliferative tumors were excluded. A total of 153 patients aged 32-74 years were enrolled for this study.

\section{Data collection techniques}

Data were collected during structured face-to-face interviews using standard forms. These were arranged either during the first clinical appointment (36\%) while the remaining interviews were scheduled during subsequent follow up visits (64\%). All interviews were conducted by a trained physician (AS), to minimize observer bias, and the mean time for each was 27.5 minutes.

Information collected include demographic (age, education, ethnicity, etc.); history of presenting complaint and cause of referral; medical (past history of benign or malignant breast disease); family history of breast cancer; reproductive (e.g. menarche, age of marriage and birth of the first live child, durations of pregnancy and lactation, and menopause).

\section{Andersen's Model of Total Patient Delay}

Andersen and Cacioppo (1995) have created a model in which they divided duration of delay into five stages (appraisal, illness, behavioral, scheduling, and treatment). Our patients were asked to specify duration they spend in each.

\section{Statistical analysis}

All statistical analyses were performed using the Statistical Package for Social Sciences (SPSS), version 23.0 (SPSS, Chicago, IL). Categorical variables were reported in numbers and percentages $(\mathrm{N}, \%)$. Whereas, continuous variables were expressed either as median or mean \pm standard deviation (SD) at $95 \%$ confidence interval (CI) depending on type of distribution. Statistical methods used were chi-square and $\mathrm{McNemar}$ tests for contingency tables, 2-way independent t-test to compare averages of both groups for each independent variable, one-way analysis of variance (ANOVA) for studying intergroup differences, and univariate analysis with binominal and multinominal regression to calculate Odd Ratio (OR), p-value $<0.05$.

\section{Ethical concerns}

Ethical clearance of the Research Ethics Committee in National Academy of Health Sciences was obtained. Institutional approvals were also received prior to commencing research. Our study strictly followed Declaration of Helsinki. Informed consents were obtained from all participants after ensuring anonymity.

\section{Results}

Overall, 184 patients referred to our facilities during study period. 63 of them were incorporated in our study after assessment for eligibility. Age of participants in our study ranging from 22 to 91 years around a mean of $46.89( \pm 14.99)$ years. Though the patients presented later (age $=47.85 \pm 15.55$ years) were elder than their counterparts (age $=44.06 \pm 13.28$ years), the difference was insignificant (p-value $=0.387 ; \mathrm{df}=61 ; 95 \% \mathrm{CI},-12.48-4.91$ ).

Married subjects constituted $88.88 \%$ of the participants. Three quarter of them came after 3 months after identifying the abnormality. This was not significantly different from the $71.43 \%$ rate expressed by bachelors $\left(\chi^{2}=0.042 ; \mathrm{df}=1\right.$, $\mathrm{p}$-value $=0.838)$. Almost two third $(65.08 \%)$ of the subjects we studied were educated. However, this had no impact on the time of presentation $\left(\chi^{2}=0.063 ; \mathrm{df}=1, \mathrm{p}\right.$-value $\left.=0.802\right)$. The percentage of literate who spent $>3$ months ahead of referral $(72.73 \%)$ was close to that of their analogues $(75.61 \%)$. Only 7 of the educated received a university qualification, whereas most of them commenced only the primary level of education ( $\mathrm{N}=25 ; 60.98 \%)$.

Most of our sample are housewives and fulltime mothers making employment rate as low as $15.87 \%$. Above $70 \%$ of each group had their symptoms for more than a quarter of a year before their first clinical visit. $77.36 \%$ of respondents declared an annual income that is under the level of GDP per Capita. Time of presentation was invariably similar among both groups regardless of the income $\left(\chi^{2}=1.338 ; \mathrm{df}=1, \mathrm{p}\right.$-value $\left.=0.247\right)$. Urban areas host a total of $69.84 \%$ of our patients. Geographically, about $58.7 \%$ of the individuals been studied came from central Sudan. Khartoum state gave rise to about half of sample. Galeyeen tribe was the predominant ethnicity accounting alone for $17.5 \%$.

\section{Clinical features of the patients:}

About $27 \%$ of the cases were recurrences. $76.09 \%$ of patients complained of primary tumors and $70.89 \%$ of those who developed secondaries arrived late $(\chi 2=0.198$; $\mathrm{df}=1$, $\mathrm{p}$-value $=0.656) .31 .75 \%$ of our sample had at least one relative diagnosed with $\mathrm{BC}$. One quarter of respondents with either positive or negative family history referred during the first 3 months. That resulted in an insignificant difference in terms of time at presentation $\left(\chi^{2}=0.002 ; \mathrm{df}=1\right.$,

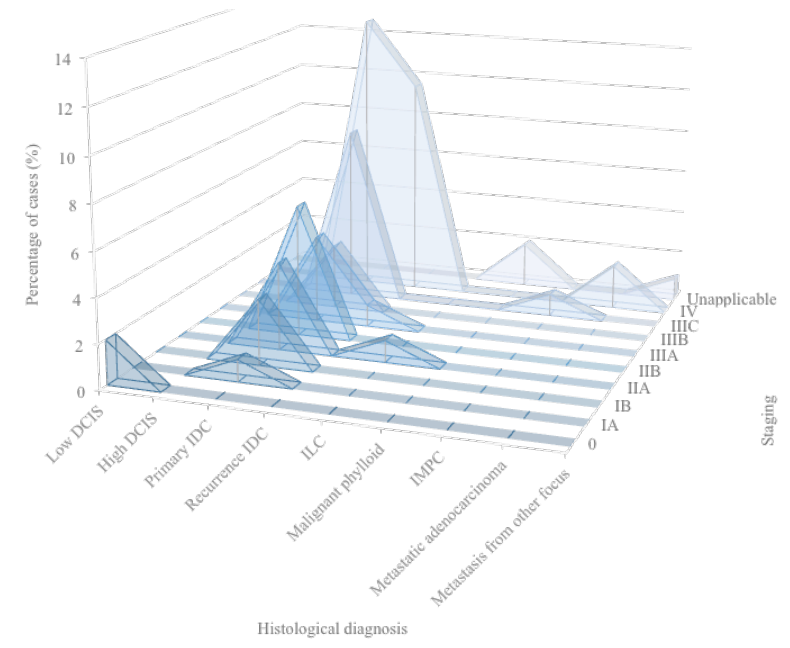

Figure 1. Histological Classification and Manchester Staging of Our 63 Patients with BC 
Table 1. Binominal and Multinominal Regression Analysis of Potential Factors that Determine Presentation

\begin{tabular}{|c|c|c|c|c|c|c|c|c|}
\hline \multicolumn{2}{|c|}{ Cutoff } & \multicolumn{6}{|c|}{ Binominal (binary) analysis } & \\
\hline \multirow{2}{*}{ Factors } & \multirow{2}{*}{$\mathrm{N}(\%)$} & \multicolumn{2}{|c|}{3 months } & \multicolumn{2}{|c|}{6 months } & \multicolumn{2}{|c|}{12 months } & \\
\hline & & OR & $\mathrm{p}$ & OR & $\mathrm{p}$ & OR & $\mathrm{p}$ & \\
\hline Age & $63(100)$ & 1.02 & 0.38 & 1 & 0.8 & 1.02 & 0.44 & \\
\hline \multicolumn{9}{|l|}{ Marital status: } \\
\hline Married & $7(11.1)$ & 1 & & 1 & & 1 & & \\
\hline Single & $56(88.9)$ & 1.2 & 0.84 & 1.35 & 0.71 & 7.04 & 0.99 & \\
\hline \multicolumn{9}{|l|}{ Education: } \\
\hline Illiterate & $22(34.9)$ & 1 & & 1 & & 0.98 & 0.97 & \\
\hline Literate & $41(65.1)$ & 1.16 & 0.8 & 1.01 & 0.99 & 1 & & \\
\hline \multicolumn{9}{|l|}{ Occupation: } \\
\hline Unemployed & $53(84.1)$ & 1.32 & 0.72 & 1.94 & 0.34 & 1.58 & 0.59 & \\
\hline Employed & $10(15.9)$ & 1 & & 1 & & 1 & & \\
\hline \multicolumn{9}{|l|}{ Annual income: } \\
\hline$<$ GDP per Capita & $53(84.1)$ & 2.28 & 0.26 & 3.18 & 0.1 & 1 & & \\
\hline$\geq$ GDP per Capita & $10(15.9)$ & 1 & & 1 & & 1.19 & 0.82 & \\
\hline \multicolumn{9}{|l|}{ Residency: } \\
\hline Rural & $19(30.2)$ & 1 & & 1 & & 1 & & \\
\hline Urban & $44(69.8)$ & 1.57 & 0.46 & 1.02 & 0.97 & 1.05 & 0.94 & \\
\hline \multicolumn{9}{|l|}{ Previous BC: } \\
\hline NA & $58(92.1)$ & 15.3 & 0.02 & 3.59 & 0.99 & 6.7 & 0.99 & \\
\hline YA & $5(7.94)$ & 1 & & 1 & & 1 & & \\
\hline \multicolumn{9}{|c|}{ Previous breast diseases: } \\
\hline NA & $46(73.0)$ & 1.3 & 0.66 & 1.31 & 0.64 & 2.04 & 0.32 & \\
\hline YA & $17(27.0)$ & 1 & & 1 & & 1 & & \\
\hline Family history: & & & & & & & & \\
\hline NA & $43(68.3)$ & 1 & & 1 & & 1 & & \\
\hline YA & $20(31.8)$ & 1.03 & 0.96 & 1.1 & 0.87 & 1.25 & 0.71 & \\
\hline BC Knowledge: & & & & & & & & \\
\hline NA & $25(39.7)$ & 3.81 & 0.06 & 5.25 & 0 & 2.11 & 0.2 & \\
\hline YA & $38(60.3)$ & 1 & & 1 & & 1 & & \\
\hline Cutoff & & & & Multino & ainal analysis & & & \\
\hline Cutort & $<3 \mathrm{~mol}$ & & & $3-12$ months & & & $>12$ months & \\
\hline Factors & $\mathrm{N}(\%)$ & $\mathrm{OR}$ & $\mathrm{N}(\%)$ & $\mathrm{OR}(\mathrm{p})$ & $95 \% \mathrm{CI}$ & $\mathrm{N}(\%)$ & $\mathrm{OR}(\mathrm{p})$ & $95 \% \mathrm{CI}$ \\
\hline Age & $16(25.4)$ & 1 & $30(47.6)$ & $1.02(0.51)$ & $0.97-1.06$ & $17(27.0)$ & $1.03(0.32)$ & $0.98-1.08$ \\
\hline Marital status: & & & & & & & & \\
\hline Married & $2(3.17)$ & 1 & $5(7.94)$ & $1.06(0.93)$ & $0.29-3.95$ & $0(0.00)$ & & \\
\hline Single & $14(22.2)$ & & $25(39.7)$ & & & $17(26.98)$ & $0.83(0.81)$ & $0.20-3.56$ \\
\hline Education: & & & & & & & & \\
\hline Illiterate & $6(9.5)$ & & $10(15.9)$ & & & $6(9.5)$ & & \\
\hline Literate & $10(15.9)$ & 1 & $20(31.8)$ & $0.83(0.78)$ & $0.24-2.95$ & $11(17.5)$ & $0.91(0.90)$ & $0.22-3.76$ \\
\hline Occupation: & & & & & & & & \\
\hline Unemployed & $13(20.6)$ & 1 & $25(39.7)$ & $1.15(0.86)$ & $0.24-5.61$ & $15(23.8)$ & $1.73(0.58)$ & $0.25-12.01$ \\
\hline Employed & $3(4.8)$ & & $5(7.9)$ & & & $2(3.2)$ & & \\
\hline Annual income: & & & & & & & & \\
\hline$<$ GDP per Capita & $12(19.1)$ & 1 & 27 (42.9) & $3.00(0.19)$ & $0.58-15.53$ & $14(22.2)$ & $1.56(0.61)$ & $0.29-8.38$ \\
\hline$\geq$ GDP per Capita & $4(6.35)$ & & $3(4.8)$ & & & $3(4.8)$ & & \\
\hline Residency: & & & & & & & & \\
\hline Rural & $6(9.5)$ & & $8(12.7)$ & & & $5(7.9)$ & & \\
\hline Urban & $10(15.9)$ & 1 & $22(34.9)$ & $0.60(0.45)$ & $0.17-2.22$ & $12(19.1)$ & $0.69(0.62)$ & $0.16-2.97$ \\
\hline Previous BC: & & & & & & & & \\
\hline NA & $12(19.1)$ & & $29(46.0)$ & & & $17(27.0)$ & & \\
\hline YA & $4(6.35)$ & 1 & $1(1.59)$ & $9.6(<0.00)$ & $9.55-9.75$ & $0(0.00)$ & $9.3(<0.00)$ & $9.33-9.33$ \\
\hline $\begin{array}{l}\text { Previous breast } \\
\text { diseases: }\end{array}$ & & & & & & & & \\
\hline NA & $11(17.5)$ & 1 & $21(33.3)$ & $1.06(0.93)$ & $0.29-3.95$ & $14(22.2)$ & $0.83(0.81)$ & $0.81-3.56$ \\
\hline YA & $5(7.9)$ & & $9(14.29)$ & & & $3(4.76)$ & & \\
\hline Family history: & & & & & & & & \\
\hline NA & 11 (17.5) & 1 & $21(33.3)$ & $1.06(0.93)$ & $0.28-3.94$ & $11(17.5)$ & & \\
\hline YA & $5(7.9)$ & & $9(14.29)$ & & & $6(9.5)$ & $0.83(0.81)$ & $0.20-3.56$ \\
\hline BC Knowledge: & & & & & & & & \\
\hline NA & $3(4.76)$ & 1 & $13(20.63)$ & $3.31(0.11)$ & $0.78-14.10$ & $9(14.29)$ & $4.88(0.05)$ & $1.01-23.57$ \\
\hline YA & $13(20.63)$ & & $17(26.98)$ & & & $8(12.70)$ & & \\
\hline
\end{tabular}




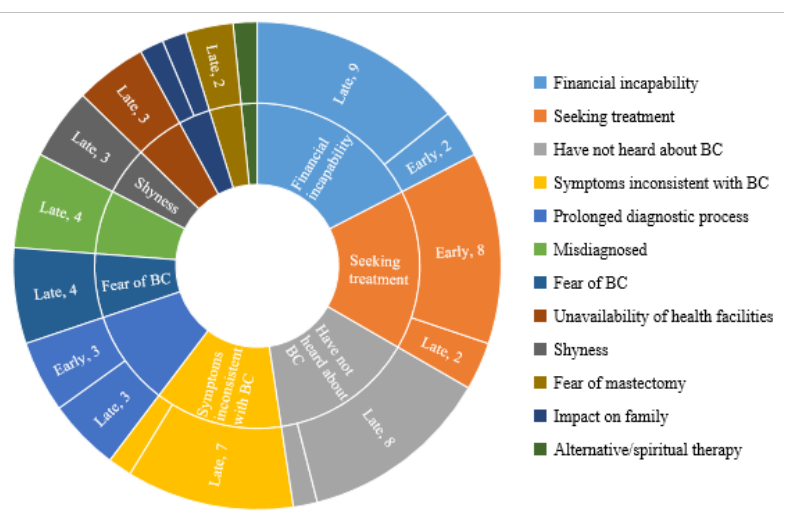

Figure 2. Factors Delaying Presentation of Breast Cancer

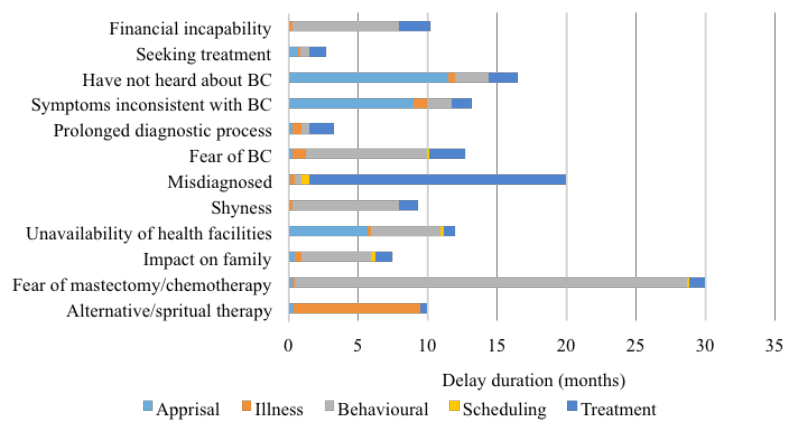

Figure 3. Andersen Model for Sudanese BC Delayed Presentation

$\mathrm{p}$-value $=0.961$ ). All subjects complained of breast lumps. $19(30.16 \%)$ patients had multiple presenting complaints, $84.21 \%$ of them detained in seeking medical help. The top second complaint was breast pain in $78.94 \%$. The lump was fungating in $4(6.4 \%)$ patients, a couple had upper limb swelling (3.2\%), and a single patient expressed nipple discharge $(1.6 \%)$. All cases were managed surgically apart of a single couple (3.2\%) which received palliative care. Excised lumps were diagnosed histopathologically and matched with the clinical staging (Figure 1).

A quarter of our patients (25.4\%) presented early during the course of their illness ( $<3$ months). Another $30(47.7 \%)$ consulted us during the next 9 months. The remaining $27 \%$ took more than a year prior to seek medical advice. The overall duration of patient delay in our study was $11.86( \pm 11.24)$ months with a range of 0.10-48.0 months. However, a comparison between the delayed and non-delayed cohorts showed a statistically significant difference between them with means of 15.26 $( \pm 11.11)$ and $1.90( \pm 1.15)$ months of delay, respectively (p-value $<0.001 ; \mathrm{df}=61 ; 95 \%$ CI, -18.95 - -7.76). Similarly, a univariate analysis of different demographic and clinical factors that may prolong referral time showed that having a past medical history was the only determinant of early presence.

\section{Factors delay presentation of breast cancer:}

Our participants listed 12 different self-determined reasons for why they sought medical care. Financial incapability, seeking treatment, and ignorance about BC were the three most frequent factors given by $11(17.46 \%)$, $10(15.87 \%)$, and $9(14.29 \%)$ respondents, respectively. Most of the subjects present within 3 months of onset of symptoms were seeking treatment for their condition. Similarly, this factor was the only why predominantly selected by the group presented early $8(80 \%)$, and consequently the sole determinant of early referral (Pearson $\chi^{2}=18.71, \mathrm{p}<0.001$ ).

Prolonged diagnostic process $(\mathrm{n}=6 ; 9.52 \%)$ and impact on family ( $\mathrm{n}=2 ; 3.17 \%)$ were equally chosen by both groups. Fear of diagnosis with BC, misdiagnosed cases, shortage of medical facilities, shyness, fear of mastectomy, alternative and spiritual therapy in form of traditional healing where exclusively present in the group complained of the symptoms for $>3$ months prior to presentation.

Although $38(60.32 \%)$ respondents had a prior knowledge about $\mathrm{BC}$ before being diagnosed, only 13 (34.21\%) presented during the first 3 months. 25 (39.68\%) patients had no knowledge about the disease, $22(88.00 \%)$ of them present late. This difference was statistically significant (Pearson $\chi^{2}=3.926 ; \mathrm{df}=1 ; \mathrm{p}=0.048$ ). However, it was not enough to signify knowledge as a predictor for the time of presentation (Wald $\chi^{2}=3.614 ; \mathrm{OR}=0.262$, $\mathrm{p}=0.057$ ).

Source of knowledge was invariably different among the group aware of the disease (Pearson $\chi 2=4.503 \mathrm{df}=5$; $\mathrm{p}=0.479)$. Almost two third of our patients $(63.16 \%)$ received their information about $\mathrm{BC}$ from television $(\mathrm{n}=13 ; 34.21 \%)$ and community-based sources $(\mathrm{n}=11$; $28.95 \%$ ) like discussions and chats with family members and friends "wanasa". The remaining 3 sources include: physicians $(\mathrm{n}=7 ; 18.42 \%)$, radio $(\mathrm{n}=5 ; 13.16 \%)$, and $\mathrm{BC}$ awareness campaigns $(n=2 ; 5.26 \%)$.

\section{Discussion}

Late presentation of Sudanese BC patients has been reported previously (Abuidris et al., 2008). However, causes of this delay were not studied thoroughly. To the best of our knowledge this is the first ever study of this issue in Sudan. Self-reported causes of delay and diagnosis time were previously reported in a single study conducted by Alawad et al. (2013) as part of the demographic characteristics of the sample. Their average duration between recognition of symptoms and diagnosis was 1 year which is almost similar to our 11.86 months diagnosis time. Such extraordinary long period was the second only to the 29 months reported in a neighboring country, Uganda (Galukande et al., 2014). All of the three diagnosis times exceed durations reported in many developed and developing countries (Montella et al., 2001). With $74.6 \%$ of the respondents came later than the first 3 months, our sample lies far beyond the range of $14 \%$ to $73 \%$ (mean $33.1 \% \pm 19.5 \%$ SD) observed across the globe (Brzozowska et al., 2014; Khan et al., 2015).

None of the demographic factors was able to predict presentation time. Many studies linked advanced ages, i.e. seniors, with late presentation (Facione, 1993; Ramirez et al., 1999; Stapleton et al., 2011). This is exactly at odd to our findings that did not correlate both issues. Marital status stands out as a highly debatable issue. The non-significant association resulted matches Innos et al. (2013) and Ramirez et al. (1999) findings. Harirchi et al. (2005) conclusions of a presence of positive relation 
between marriage and late presentation, contradicts what other studies have reached (Thongsuksai et al., 2000; Ali et al., 2008; Kumari and Goonewardena, 2001). Our conclusions which did not associate both education and occupation with presentation category are in keeping with many reports (Norsa'adah et al., 2011; Cheng et al., 2015). In contrast, poor socioeconomic status (Khan et al., 2015) and residence in a rural area (Nguyen et al., 2014) have been found to deter seeking for medical help. However, we did not identify existence of such a relation among our patients. This may be attributed to the fact that more than three quarters of the sample lie below poverty line $(77.36 \%)$, and $69.84 \%$ of it lives in urbans.

Clinically, a positive past medical history of BC leads patients to have an early clinical visit as symptoms appear. $\mathrm{BC}$ recurrence is common in Sudan among different age groups (Alawad, 2014), Gismalla et al. (2014) estimated its rate as $31.1 \%$. Our conclusion that denied any relationship between presentation and family history of $\mathrm{BC}$ was consistent with a report from another low income country (Odongo et al., 2015). Other studies detected an inverse relation between the factors (Poum et al., 2014; Khan et al., 2015).

Justifications given by the respondents were organized into themes. Most of the early comers were basically aiming for a cure for their condition. The other group mostly attributed their late arrival to financial incompetence, ignorance about $\mathrm{BC}$, and attribution of symptoms to other diseases. Our findings that, among those reasons, make the priority for financial obstacles is consistent with a preceding Sudanese study (Alawad et al., 2013). Also it is shared by a couple of studies from two countries at the extremes of economic prosperity, Nigeria and US (Pruitt et al., 2015; Ruddy et al., 2014). Many studies have addressed the role of lack of knowledge in deterring presentation (Memon et al., 2013; Bodapati and Babu, 2013). This was inapplicable to the $14.6 \%$ of our patients who have not heard about the disease prior to diagnosis. Our rate is higher than the other one available in Sudan (6.9\%) (Alawad et al., 2013), though Alawad et al. (2013) did not determine level of significance of this figure. The one eighth of our patients who did not consider $\mathrm{BC}$ as an underlying cause for their condition, were basically perceive it as a self-limiting or attributed it to other benign diseases. This trend of interpretation has been previously reported (Andersen and Cacioppo, 1995). It was linked to the symptom detected first and the rate of its progression (Norsa'adah et al., 2011). As all of our patients had breast lumps from the start, they may develop a false sense that mitigates the seriousness of having a breast mass. Moreover, Piñeros et al. (2009) highlighted that, in developing countries, lack of pain makes the lump usually thought of as harmless.

In conclusion, A past medical history of breast cancer significantly motivates patients to have an early leg soon as the tumor recurs. This highlights failure of currently used awareness rising strategies in emphasizing how serious the disease is. Willingness to find treatment was the sole determinant of timely referral. Reasons drive Sudanese breast cancer patients to seek medical advice are of great variety. Typically, they are inconsistent with the period that precedes presentation. Therefore, exploring other factors that were infeasible for us to study is strongly recommended. For instance, usage of distance separates the patient from the nearest health facility or the duration of journey rather than place of residency, which gives an indicator as most of the rural areas in the country lack such facilities.

\section{Acknowledgements}

The authors would like to thank Dr. Adil E Yousif, Associate professor of statistics, College of Arts and Sciences, Qatar University, Qatar, and Prof. Mustafa Numairi, Professor of Biostatistics, Faculty of Medicine, Neelain University, Sudan, for their endless encourage and support.

\section{References}

Abuidris D, Elgaili E, Rahman M, Mohammed S (2008). Female breast cancer in Central Sudan-A tragedy of young age and late presentation. Cancer Res, $\mathbf{6 8}, 3851$.

Alawad ALM (2014). Evaluation of clinical and pathological response after two cycles of neoadjuvant chemotherapy on sudanese patients with locally advanced breast cancer. Ethiop $J$ Health Sci, 24, 15-20.

Alawad AA, Alshiekh AA, Alhaj AM (2013). Demographic characteristics and review of patients with locally advanced breast cancer in Sudan. Afrimedic J, 4, 5-8.

Ali R, Mathew A, Rajan B (2008). Effects of socio-economic and demographic factors in delayed reporting and late-stage presentation among patients with breast cancer in a major cancer hospital in South India. Asian Pac J Cancer Prev, 9, 703-7.

Andersen BL, Cacioppo JT (1995). Delay in seeking a cancer diagnosis: delay stages and psychophysiological comparison processes. Br J Soc Psychol, 34, 33-52.

Benson JR, Jatoi I (2012). The global breast cancer burden. Future Oncol, 8, 697-702.

Binder M, Roberts C, Spencer N, Antoine D, Cartwright C (2014). On the Antiquity of Cancer: Evidence for Metastatic Carcinoma in a Young Man from Ancient Nubia (c. 1200BC). PLOS ONE, 9, 90924.

Bodapati SL, Babu GR (2013). Oncologist perspectives on breast cancer screening in India - results from a qualitative study in Andhra Pradesh. Asian Pac J Cancer Prev, 14, 5817-23.

Brzozowska A, Duma D, Mazurkiewicz T, Brzozowski W, Mazurkiewicz M (2014). Reasons for delay in treatment of breast cancer detected due to breast self-examination in women from the Lubelskie region. Ginekol Pol, 85, 14-7.

Cancer Research UK (2012). Lifetime risk of breast cancer[homepage on the Internet]. London: July 26.

Cheng MA, Ling DY, Nanu PKP, Nording H, Lim CH (2015). Factors influencing late stage of breast cancer at presentation in a district Hospital, Segamat Hospital, Johor. Med J Malaysia, 70, 148-52.

Facione NC (1993). Delay versus help seeking for breast cancer symptoms: a critical review of the literature on patient and provider delay. Soc Sci Med, 36, 1521-34.

Ferlay J, Soerjomataram I, Dikshit R, et al (2015). Cancer incidence and mortality worldwide: Sources, methods and major patterns in GLOBOCAN 2012. Int J Cancer, 136, 359-86.

Fregene A, Newman LA (2005). Breast cancer in sub-Saharan Africa: how does it relate to breast cancer in African- 


\section{Alaaddin M Salih et al}

American women?. Cancer, 103, 1540-50.

Galukande M, Mirembe F, Wabinga H (2014). Patient delay in accessing breast cancer care in a sub saharan african country: uganda. Br J Med Med Res, 4, 2599-610.

Gismalla MD, Alawad AMA, Alshaihk AA, Alhaj A, Mohamed ME (2014). Factors associated with local recurrence after mastectomy for invasive breast cancer in Sudanese patients. Intl Res Med Sci, 2, 26-30.

Harirchi I, Ghaemmaghami F, Karbakhsh M, Moghimi R, Mazaherie $\mathrm{H}$ (2005). Patient delay in women presenting with advanced breast cancer: An Iranian study. Public Health, 119, 885-91.

Innos K, Padrik P, Valvere V, Eelma E, Kütner R, Lehtsaar J, Tekkel M (2013). Identifying women at risk for delayed presentation of breast cancer: a cross-sectional study in Estonia. BMC Public Health, 13, 947.

Khan MA, Hanif S, Iqbal S, Shahzad MF, Shafique S, Khan MT (2015). Presentation delay in breast cancer patients and its association with sociodemographic factors in North Pakistan. Chin J Cancer Res, 27, 288-93.

Kumari PBVR, Goonewardena CSE (2001). Delay among women reporting symptoms of breast cancer. J Coll Comm Physc Sri Lanka, 16, 17-22.

Memon ZA, Shaikh AN, Rizwan S, Sardar MB (2013). Reasons for patient's delay in diagnosis of breast carcinoma in Pakistan. Asian Pac J Cancer Prev, 14, 7409-14.

Montella M, Crispo A, D'Aiuto G, et al (2001). Determinant factors for diagnostic delay in operable breast cancer patients. Eur J Cancer Prev, 10, 53-9.

Nguyen-Pham S, Leung J, McLaughlin D (2014). Disparities in breast cancer stage at diagnosis in urban and rural adult women: a systematic review and meta-analysis. Ann Epidemiol, 24, 228-35.

Norsa'adah B, Rampal KG, Rahmah MA, Naing NN, Biswal BM (2011). Diagnosis delay of breast cancer and its associated factors in Malaysian women. BMC Cancer, 11, 141.

Odongo J, Makumbi T, Kalungi S, Galukande M (2015). Patient delay factors in women presenting with breast cancer in a low income country. BMC Res Notes, $8,467$.

Parkin DM, Bray F, Ferlay J, Pisani P (2005). Global cancer statistics, 2002. CA Cancer J Clin, 55, 74-108.

Piñeros M, Sánchez R, Cendales R, Perry F, Ocampo R (2009). Patient delay among Colombian women with breast cancer. Salud Publica Mex, 51, 372-80.

Poum A, Promthet S, Duffy SW, et al (2014). Factors associated with delayed diagnosis of breast cancer in northeast Thailand. J Epidemiol, 24, 102-8.

Pruitt L, Mumuni T, Raikhel E, et al (2015). Social barriers to diagnosis and treatment of breast cancer in patients presenting at a teaching hospital in Ibadan, Nigeria. Glob Public Health, 10, 331-44.

Ramirez AJ, Westcombe AM, Burgess CC, Sutton S, Littlejohns P, Richards MA (1999). Factors predicting delayed presentation of symptomatic breast cancer: a systematic review. Lancet, 353, 1127-31.

Ruddy KJ, Gelber S, Tamimi RM, et al (2014). Breast cancer presentation and diagnostic delays in young women. Cancer 120, 20-25.

Stapleton JM, Mullan PB, Dey S, Hablas A, Gaafar R, Seifeldin IA, Banerjee M, Soliman AS (2011). Patient-mediated factors predicting early- and late-stage presentation of breast cancer in Egypt. Psychooncol, 20, 532-7.

Thongsuksai P, Chongsuvivatwong V, Sriplung H (2000). Delay in breast cancer care: a study in Thai women. Med Care, 38, 108-14.

Unger-Saldaña K (2014). Challenges to the early diagnosis and treatment of breast cancer in developing countries. World $J$ Clin Oncol, 5, 465-77. 